\section{Influence of carer expressed emotion and affect on relapse in non-affective psychosis}

\author{
E. KUIPERS, P. BEBBINGTON, G. DUNN, D. FOWLER, D. FREEMAN, \\ P. WATSON, A. HARDY and P. GARETY
}

High expressed emotion in carers predicts an increased relapse rate in schizophrenia (Bebbington \& Kuipers, 1994; Butzlaff \& Hooley, 1998). This finding led to the development of family interventions, which were recently endorsed by the National Institute for Clinical Excellence (NICE) guidelines on schizophrenia (National Institute for Clinical Excellence, 2003). However, it is not known how critical, hostile or overinvolved family relationships lead to the re-emergence of psychosis. Our cognitive model of psychosis (Garety et al, 2001) posits that family environments achieve this via affect, and that patients living with carers who show high expressed emotion would have higher levels of anxiety and depression and lower selfesteem, but not more symptoms of psychosis. Previous studies have shown that high expressed emotion is 'not an artefact of patient morbidity' (Leff \& Vaughn, 1985: p. 105). As in earlier studies (Barrowclough \& Hooley, 2003; Raune et al, 2004), we also predicted that carers who show high expressed emotion would have higher levels of 'burden', stress, depression and avoidant coping style, and lower self-esteem.

\section{METHOD}

\section{Participants}

The study sample consisted of participants recruited for the Psychological Prevention of Relapse in Psychosis (PRP) Trial (ISRCTN83557988) and their immediate carers. The PRP is a UK multicentre randomised controlled trial of cognitivebehavioural therapy and family intervention for psychosis, designed to test hypotheses about outcome and about the psychological processes associated with psychosis for both carers and participants. Studies of psychological processes linked with psychosis were incorporated into the baseline assessment of carers and participating patients, and were conducted before randomisation into the trial.

The trial was based in four National Health Service (NHS) trusts in London and East Anglia in the UK. Within each of these trusts, recruitment was from specified in-patient and out-patient teams which agreed that all patients who met the eligibility criteria would be asked to participate in the trial. These services were canvassed at least fortnightly for patients with psychosis who were relapsing. Patients who fulfilled the eligibility criteria were asked to give their informed consent. Patients with carers who were in contact (including telephone contact) with them for at least $10 \mathrm{~h}$ a week were also asked to give their consent to be contacted. These carers were then asked for their consent to enter the trial. Patients were recruited at the time of a re-emergence of positive symptoms, either from a previously recovered state or from a state of persistent symptoms. For patients with persistent symptoms, a significant exacerbation in positive symptoms, typically leading to hospital admission, was required. The inclusion criteria were as follows: current diagnosis of non-affective psychosis (schizophrenia, schizoaffective psychosis, delusional disorder; ICD-10 F20; World Health Organization, 1992); age 18-65 years; a second or subsequent episode starting not more than 3 months before the patient consented to enter the trial; and a rating of at least 4 (moderate severity) on at least one positive psychotic symptom of the Positive and Negative Syndrome Scale (PANSS; Kay, 1991) at the first time of meeting.

A total of 86 patients and their carers who had consented to take part in the PRP trial were included in this study.

\section{Design}

This was a cross-sectional study. The data were obtained by trained assessors during the baseline phase of the randomised controlled trial, before allocation.

\section{Carer measures}

Camberwell Family Interview (CFI; Vaughn \& Leff, 1976). This is a semi-structured questionnaire that assesses how well carers get on with the person who has had a recent episode of psychosis. It covers family relationships, arguments, time spent together, symptoms and role functioning. With the carer's consent this interview is recorded 
on audiotape, and it is subsequently rated for expressed emotion. Ratings are based not only on content of speech but also on prosodic variables such as pitch, speed and tone. Five scales are rated: critical comments (frequency count); hostility (score of 0,1 or 2 ); warmth (0-5); emotional overinvolvement (0-5); and positive remarks (frequency count). More than six critical comments, any hostility, or a rating of 3 or higher for emotional overinvolvement categorise a carer as showing high expressed emotion. Taped interviews were rated by assessors previously trained by Dr Christine Vaughn to give reliable ratings of expressed emotion. High correlations or phi coefficients were obtained for all expressed emotion scales: $>0.76$ for critical comments, hostility, emotional overinvolvement, warmth, positive remarks and overall expressed emotion category.

Experience of Caregiving Inventory $(\mathrm{ECl}$; Szmukler et al, 1996). This is a 66-item instrument that assesses the subjective experience of caregiving in eight areas (difficult behaviour, negative symptoms, stigma, problems with services, effects on the family, need to provide back-up, dependency and loss), together with two areas of positive experiences of caring (positive personal experiences and positive aspects of the relationship). The questionnaire measures how often carers have thought about each issue during the past month before interview (on a rating scale where $0=$ never, $1=$ rarely, $2=$ sometimes, $3=$ often and $4=$ nearly always).

Self-Esteem Scale (Rosenberg, 1965). This measure consists of 10 items, each measured on a 4-point scale ranging from 'strongly agree' to 'strongly disagree'. After reverse scoring, the items were summed and divided by 10 to obtain a mean self-esteem score. A high score represents low selfesteem.

General Health Questionnaire (GHQ; Goldberg $\&$ Williams, 1988). The 28-item version of this instrument was used, with scoring of $0-4$. It has a total score and four subscales (somatic symptoms, stress, social functioning and depression). In this study we focused on the stress and depression subscales.

COPE Inventory (Carver et al, 1989; Carver \& Scheier, 1994). This is a multidimensional inventory that assesses different coping styles (on a scale where $1=$ never, $2=$ rarely, arely, $3=$ sometimes and $4=$ a lot). The total score for each scale is obtained by adding the items together. The present study used two questions per scale from the short form of the measure (Carver \& Scheier, 1994). As in a previous study by Raune et al (2004), we used an avoidant coping subscale consisting of 8 items $(2$ items from each of the following: behavioural disengagement, mental disengagement, alcohol/drug use and denial).

\section{Patient measures}

PANSS (Kay, 1991). This is a 30-item instrument (rated on a scale from 1 to 7) for the assessment of phenomena associated with schizophrenia. Symptoms during the past $72 \mathrm{~h}$ are rated, and higher scores indicate more severe symptoms. The positive symptoms sub-scale and negative symptoms sub-scale each consist of 7 items, and there is also a general pathology subscale consisting of 16 items.

Self-Esteem Scale (Rosenberg, 1965). (see above).

Beck Depression Inventory-II (BDI-II; Becket al, 1996). This established instrument consists of 21 items, each of which is measured on a scale ranging from 0 to 3 . The total BDI-II score thus ranges from 0 to 63 , with a high score representing a higher level of symptoms. Depression is measured for the previous 2 weeks. Birchwood et al (2000) have reported a high correlation $(r=0.91)$ between the BDI and the interview-based Calgary Depression Scale for Schizophrenia (Addington et al, 1993), which confirms that the BDI can be used to assess depression in psychosis.

Beck Anxiety Inventory (BAl; Beck et al, 1988). This measure consists of 21 items, each of which measures common anxiety symptoms. The total anxiety score ranges from 0 to 63 , with a higher score representing a higher level of anxiety. Anxiety is measured for the previous week.

\section{Data analysis}

All analyses were performed using SPSS for Windows (version 12.01). Using independent-sample $t$-tests, we first investigated the relationships between high and low expressed emotion carers and patient variables (anxiety, depression, self-esteem and overall symptoms of psychosis).

We next related the components of expressed emotion (emotional overinvolvement, hostility, critical comments, warmth and positive remarks) to patients' symptoms using Pearson's correlations, followed by multiple linear regression to control for potential confounding effects. Finally, we looked at the correlations between carer expressed emotion variables and carer characteristics.

\section{RESULTS}

\section{Patient and carer characteristics}

Around half of the carers were the parents of patients, and three-quarters of the remainder were spouses or partners (Tables 1 and 2). The mean age of carers was consequently higher than that of patients (carer mean age 52.9 years, range 26-86 years; participant mean age 36.3 years, range 18-46 years). Patients were defined by not being in their initial episode, and the mean duration of illness was 11.2 years (range $<1$ year to 44 years).

In total, $72 \%$ of the patients were male, and $84 \%$ were White. The relatively small proportion of patients from a Black ethnic background $(7 \%)$ may be accounted for by the low overall proportion of patients with carers in the inner-city areas of the study locations. Nearly $80 \%$ of the patients were unemployed, which is consistent with the poor general employment prospects of people with psychosis (Marwaha \& Johnson, 2004). Less than a quarter of the patients were living with partners, and nearly two-thirds were single. For carers, the gender ratio was (as usual) reversed, with only $30 \%$ being male.

In total, $36 \%$ of carers were given a high overall rating of expressed emotion, and $30 \%$ had a high rating for expressed emotion on the basis of critical comments, $24 \%$ on the basis of emotional overinvolvement and $13 \%$ on the basis of some hostility. The mean number of critical comments was 3.5 (range 0-32). The mean rating for emotional overinvolvement was 1.8 (range $0-5$ ), whereas the mean hostility was 0.26 (range $0-3$ ). The mean rating for warmth was 2.3 (range $0-4)$, with $43 \%$ of carers having a rating of more than 2 . The mean rating for positive remarks was 1.9 (range 0-9). These ratings were lower than those reported in the literature. For instance, $48 \%$ of carers made 
Table I Attributes of carers and patients

\begin{tabular}{|c|c|c|c|}
\hline Attribute & $\begin{array}{l}\text { Low expressed } \\
\text { emotion } \\
n / N(\%)\end{array}$ & $\begin{array}{l}\text { High expressed } \\
\text { emotion } \\
n / N(\%)\end{array}$ & $\begin{array}{c}\text { Total } \\
n / N(\%)\end{array}$ \\
\hline \multicolumn{4}{|l|}{ Gender of patient } \\
\hline Male & $40 / 55(72.7)$ & 22/31 (7I.0) & $62 / 86(72.1)$ \\
\hline Female & 15/55 (27.3) & $9 / 31(29.0)$ & $24 / 86(27.9)$ \\
\hline \multicolumn{4}{|l|}{ Gender of carer } \\
\hline Male & $17 / 55(30.9)$ & $8 / 29(27.6)$ & $25 / 84(29.8)$ \\
\hline Female & $38 / 55(69.1)$ & $2 \mathrm{I} / 29(72.4)$ & $59 / 84(70.2)$ \\
\hline \multicolumn{4}{|l|}{ Patient employment status } \\
\hline Employed & $8 / 55(14.5)$ & $3 / 31 \quad(9.7)$ & $11 / 86(12.8)$ \\
\hline Unemployed & $42 / 55(76.4)$ & $26 / 31$ (83.9) & $68 / 86(79.1)$ \\
\hline Economically inactive & $5 / 55$ & $2 / 31 \quad(7.4)$ & $7 / 86$ (8.I) \\
\hline \multicolumn{4}{|l|}{ Carer employment status } \\
\hline Employed & $21 / 53(39.6)$ & $10 / 26(38.5)$ & $31 / 79(39.2)$ \\
\hline Unemployed & 19/53 (35.8) & $10 / 26(38.5)$ & $29 / 79(36.7)$ \\
\hline Economically inactive & $13 / 53(24.5)$ & $5 / 26(19.2)$ & $18 / 79(22.8)$ \\
\hline \multicolumn{4}{|l|}{ Patient marital status } \\
\hline Single & $32 / 54(59.3)$ & 22/31 (71.0) & $54 / 85(63.5)$ \\
\hline Married & 18/54 (33.3) & 4/31 (12.9) & $22 / 85(25.9)$ \\
\hline $\begin{array}{l}\text { Divorced, widowed } \\
\text { or separated }\end{array}$ & $4 / 54 \quad(7.4)$ & $5 / 31(16.1)$ & $9 / 85(10.6)$ \\
\hline \multicolumn{4}{|l|}{ Patient cohabiting } \\
\hline Yes & 13/54 (24.I) & $7 / 30(23.3)$ & $20 / 84(23.8)$ \\
\hline No & $41 / 54(35.9)$ & $23 / 30(76.7)$ & $64 / 84(76.2)$ \\
\hline \multicolumn{4}{|l|}{ Patient ethnicity } \\
\hline White & $48 / 55(87.3)$ & 24/31 (77.4) & $72 / 86(83.7)$ \\
\hline Black & $2 / 55 \quad(3.6)$ & $4 / 31(12.9)$ & $6 / 86 \quad(7.0)$ \\
\hline Other & $5 / 55 \quad(9.1)$ & $3 / 31 \quad(9.7)$ & $8 / 86 \quad(9.3)$ \\
\hline
\end{tabular}

Table 2 Carer age, face-to-face contact and expressed emotion

\begin{tabular}{lccccc}
\hline Attribute & $n$ & Mean & Median & s.d. & Range \\
\hline Carer age (years) & 71 & 52.9 & 55.0 & 13.1 & $26-88$ \\
Duration of face-to-face contact (h) & 71 & 39.2 & 35.0 & 23.9 & $7-84$ \\
Emotional overinvolvement & 86 & 1.8 & 2.0 & 1.2 & $0-5$ \\
Hostility & 86 & 0.26 & 0.0 & 0.75 & $0-3$ \\
Critical comments & 86 & 3.5 & 2.0 & 4.6 & $0-32$ \\
Positive remarks & 86 & 1.9 & 1.0 & 1.8 & $0-9$ \\
Warmth & 86 & 2.0 & 2.0 & 1.2 & $0-4$ \\
\hline
\end{tabular}

I. The carers who had 7 hours of contact a week also had more than 3 hours of telephone contact a week.

either one or no critical comments. There was no relationship between the level of expressed emotion and any of the demographic variables analysed (gender of participant, gender of carer, participant or carer employment status, ethnicity and age), although high levels of expressed emotion were relatively unusual when the carer was married to the participant $(13 \%)$.

\section{Expressed emotion in carers and patients' symptoms}

Carers with high and low expressed emotion were compared with regard to differences in patients' symptoms using independent-sample $t$-tests. Patients whose carers had low expressed emotion had a mean BAI score of 18.7 (s.d.=14.5), whereas those whose carers had high expressed emotion had a significantly higher mean score of 25.8 (s.d.=15.9, $P=0.046$; Table 3 ). Similarly patients whose carers had low expressed emotion had a mean BDI-II score of 22.6 (s.d.=13.7), whereas those whose carers had high levels of expressed emotion had a significantly higher BDI-II score of 28.7 (s.d. $=12.1, P=0.045$ ). Contrary to our prediction, there were no significant differences in patients' self-esteem scores on the Rosenberg scale. However, as we had predicted, there were also no significant differences in patients' scores on the PANSS negative, PANSS positive or PANSS general sub-scales (although the latter approached significance, as it partly comprises anxiety and depression scores).

We next related the components of expressed emotion (emotional overinvolvement, hostility, critical comments, warmth and positive remarks) to patients' scores on the BAI, BDI-II, Rosenberg self-esteem and PANSS scales (Table 4). There were significant correlations between carer critical comments, emotional overinvolvement and patients' BAI scores, but not depression as measured on the BDI-II. Patients' self-esteem scores were significantly correlated with patients' BDI-II scores, as would be expected, but not with any components of carer expressed emotion. Patients' PANSS scores were also not correlated with carer expressed emotion, with the exception of positive remarks and the PANSS general sub-scale. It was unclear why the latter should be associated (it is not a general finding). Carer hostility was correlated with critical comments, and also with emotional overinvolvement; the negative aspects of expressed emotion were interrelated. Warmth was associated with positive remarks, and was negatively correlated with critical comments.

Given the correlations that were found between patients' BAI score, carers' critical comments and emotional overinvolvement, patient anxiety was chosen as the dependent variable in a linear regression using all of the component expressed emotion ratings. Only the frequency of critical comments made by carers predicted anxiety in patients $(P=0.01)$. The rating of hostility only contributed to the model at a trend level $(P=0.092)$.

When the same analysis was repeated using patients' BDI-II scores as the dependent variable, none of the expressed emotion components were 
Table 3 Patient symptom ratings according to expressed emotion (EE) of carers

\begin{tabular}{|c|c|c|c|c|c|c|c|}
\hline Patient symptom ratings & $n$ & Mean & s.d. & $t$ & d.f. & $\begin{array}{c}P \\
\text { (two-tailed) }\end{array}$ & $\begin{array}{c}\text { Mean } \\
\text { difference }\end{array}$ \\
\hline \multicolumn{8}{|l|}{ BAI score } \\
\hline Low EE & 51 & 18.7 & 14.5 & -2.03 & 74 & 0.046 & -7.1 \\
\hline High EE & 29 & 25.8 & 15.9 & & & & \\
\hline \multicolumn{8}{|l|}{ BDI-II } \\
\hline Low EE & 54 & 22.6 & 13.7 & -2.03 & 78 & 0.045 & -6.1 \\
\hline High EE & 30 & 28.7 & 12.1 & & & & \\
\hline \multicolumn{8}{|l|}{ PANSS positive sub-scale } \\
\hline Low EE & 55 & 16.5 & 5.2 & -1.58 & 84 & 0.12 & -1.9 \\
\hline High EE & 31 & 18.4 & 5.6 & & & & \\
\hline \multicolumn{8}{|l|}{ PANSS negative sub-scale' } \\
\hline Low EE & 55 & 14.9 & 5.0 & -0.94 & 45.5 & 0.35 & -1.4 \\
\hline High EE & 31 & 16.3 & 7.4 & & & & \\
\hline \multicolumn{8}{|l|}{ PANSS general sub-scale } \\
\hline Low EE & 55 & 33.1 & 7.8 & -1.58 & 84 & 0.06 & -3.2 \\
\hline High EE & 31 & 36.4 & 6.9 & & & & \\
\hline
\end{tabular}

BAI, Beck Anxiety Inventory; BDI-II, Beck Depression Inventory - II; PANSS, Positive and Negative Syndrome Scale. I. Equality of variance not assumed.

found to contribute significantly (see Table 5).

\section{Expressed emotion, other characteristics of carers, and patients' symptoms}

As in earlier studies, we had predicted that components of carer expressed emotion would be related to measures of burden, stress, low self-esteem and unhelpful coping strategies (e.g. avoidance) in carers. Pearson's correlations were used to examine these relationships as well as the overall relationships between carer and patient attributes.

Carers' critical comments were significantly correlated with low carer self-esteem $(r=0.30, P=0.0008)$ and with the avoidance coping strategy score on the COPE inventory $(r=0.26, P=0.026)$, and were negatively associated with reinterpretation on the COPE inventory $(r=-0.29$, $P=0.009$ ). Carer hostility towards the patient was also correlated with low carer self-esteem ( $r=0.24, P=0.033)$. However, low carer self-esteem was not directly associated with carer coping, but only indirectly via expressed emotion.

There were also significant correlations between carers' and patients' symptoms. Low carer self-esteem was associated with low patient self-esteem $(r=0.29, P=0.017)$ and with carer depression $(r=0.58$, $P<0.0005)$ and stress $(r=0.53, P<0.0005)$ on the GHQ. Low carer self-esteem was also related to patients' BDI-II score $(r=0.25, \quad P=0.029)$, and was nonsignificantly correlated with patients' BAI score $(r=0.23, P=0.052)$, but was significantly correlated with negative aspects of caregiving on the ECI (the so-called burden of care; $r=0.33, P=0.013)$. The ECI negative score was in turn associated with high carer stress scores on the GHQ $(r=0.48, P<0.0005)$ and with patient BDI scores $(r=0.28, P=0.036)$.

The significant relationships are illustrated in Fig. 1.

\section{DISCUSSION}

\section{Carer criticism and patient anxiety}

As we had predicted, carer expressed emotion was related to one aspect of patient symptoms, namely affect. High levels of carer expressed emotion, particularly criticism, predicted high levels of patient anxiety. Positive expressed emotion ratings, such as warmth, were not directly involved, although they were lower in highly critical relationships. As would be expected, the negative aspects of relationships appeared

Table 4 Correlations between carer expressed emotion and patients' symptoms'

\begin{tabular}{|c|c|c|c|c|c|c|c|c|c|c|c|}
\hline & $\begin{array}{c}\text { Emotional } \\
\text { over- } \\
\text { involvement }\end{array}$ & Hostility & $\begin{array}{c}\text { Critical } \\
\text { comments }\end{array}$ & Warmth & $\begin{array}{l}\text { Positive } \\
\text { remarks }\end{array}$ & $\begin{array}{l}\text { Patient } \\
\text { BAI } \\
\text { score }\end{array}$ & $\begin{array}{l}\text { Patient } \\
\text { BDI-II } \\
\text { score }\end{array}$ & $\begin{array}{l}\text { Patient } \\
\text { self- } \\
\text { esteem }\end{array}$ & $\begin{array}{c}\text { PANSS } \\
\text { positive } \\
\text { sub-scale } \\
\text { score }\end{array}$ & $\begin{array}{c}\text { PANSS } \\
\text { negative } \\
\text { sub-scale } \\
\text { score }\end{array}$ & $\begin{array}{c}\text { PANSS } \\
\text { general } \\
\text { sub-scale } \\
\text { score }\end{array}$ \\
\hline Emotional overinvolvement & 1.00 & $0.34 * *$ & $0.38 * *$ & 0.12 & -0.07 & $0.23 *$ & 0.08 & -0.06 & 0.11 & 0.20 & 0.10 \\
\hline Hostility & & 1.00 & $0.60 * *$ & -0.18 & -0.11 & 0.03 & 0.09 & -0.05 & -0.03 & -0.10 & -0.14 \\
\hline Critical comments & & & 1.00 & $-0.29 * *$ & -0.12 & $0.26 *$ & 0.15 & 0.02 & 0.08 & -0.15 & 0.02 \\
\hline Warmth & & & & 1.00 & $0.32^{* *}$ & 0.07 & -0.13 & -0.06 & -0.06 & 0.20 & 0.13 \\
\hline Positive remarks & & & & & 1.00 & 0.12 & -0.08 & -0.01 & 0.10 & 0.12 & $0.23 *$ \\
\hline Patient BAI score & & & & & & 1.00 & $0.52^{* *}$ & 0.22 & $0.28^{*}$ & 0.12 & $0.46^{* *}$ \\
\hline Patient BDI-II score & & & & & & & 1.00 & $0.54^{* *}$ & 0.18 & $0.34 * *$ & $0.39 * *$ \\
\hline Patient self-esteem & & & & & & & & 1.00 & 0.05 & 0.18 & 0.13 \\
\hline PANSS positive sub-scale score & & & & & & & & & 1.00 & 0.06 & $0.5 I^{* *}$ \\
\hline PANSS negative sub-scale score & & & & & & & & & & 1.00 & $0.48^{* *}$ \\
\hline PANSS general sub-scale score & & & & & & & & & & & 1.00 \\
\hline
\end{tabular}

BAI, Beck Anxiety Inventory; BDI-II, Beck Depression Inventory-II; PANSS, Positive and Negative Syndrome Scale.

$* P<0.05, * * P<0.01$

I. Pearson's correlations. 
Table 5 Linear regression of components of expressed emotion

\begin{tabular}{lrrrr} 
& \multicolumn{3}{c}{ Standardised coefficients } & \multirow{2}{*}{$95 \% \mathrm{Cl}$} \\
\cline { 2 - 4 } & \multicolumn{1}{c}{ Beta } & \multicolumn{1}{c}{$t$} & \multicolumn{1}{c}{$P$} & \\
\cline { 2 - 4 } & & & & \\
Anxiety (BAI) & 0.15 & 1.24 & 0.220 & -1.16 to 4.97 \\
$\quad$ Emotional overinvolvement & -0.24 & -1.71 & 0.092 & -10.08 to 0.77 \\
Hostility & 0.39 & 2.65 & 0.010 & 0.31 to 2.19 \\
Critical comments & 0.007 & 0.06 & 0.951 & -1.80 to 1.92 \\
Positive comments & 0.12 & 1.00 & 0.322 & -1.63 to 4.90 \\
Warmth & & & & \\
Depression (BDI-II) & 0.04 & 0.35 & 0.73 & -2.27 to 3.24 \\
Emotional overinvolvement & -0.02 & -0.15 & 0.88 & -5.33 to 4.54 \\
Hostility & 0.12 & 0.80 & 0.44 & -0.52 to 1.19 \\
Critical comments & -0.03 & -0.22 & 0.82 & -1.90 to 1.52 \\
Positive comments & -1.00 & -0.78 & 0.44 & -4.10 to 1.79 \\
Warmth & & &
\end{tabular}

BAI, Beck Anxiety Inventory; BDI-II, Beck Depression Inventory-II.

to be the most upsetting to patients who had recently had a relapse of symptoms of psychosis. We had predicted a more general effect of negative relationships on patients, with high levels of patient depression and low patient self-esteem also involved. However, our subsequent analyses suggested instead that anxiety was the main emotion found in patients with carers who showed high levels of expressed emotion. Furthermore, we found that carer criticism was implicated as the mechanism although, given that this was a cross-sectional study, this result must be treated with caution and requires replication prospectively.

\section{Carer characteristics and expressed emotion}

Relationships between carer characteristics and expressed emotion were less pronounced in this sample. Carer criticism and hostility towards patients were related to low carer self-esteem, and to carer stress and depression. Carers' critical comments were also directly related to an avoidant coping strategy, as we found previously
(Raune et al, 2004), but were not, in our study, related to negative aspects of caregiving. Instead we found that negative evaluations of caregiving (high carer 'burden') were directly related to carer stress and patient depression, but were not directly related to expressed emotion.

\section{Theoretical issues}

Our model (Garety et al, 2001) was partly supported. It is plausible, as we had proposed, that expressed emotion impacts on patients via affect, with critical comments in particular being correlated with high levels of patient anxiety. Carers inevitably find their role stressful and depressing at times, and this is sometimes demonstrated by their own low self-esteem and by high levels of hostility towards the patient. Carer 'burden' is related to carer stress and patient depression, but not directly in this sample to poor relationships (only indirectly via low carer self-esteem).

\section{Study limitations}

Our failure to replicate the finding that carer criticism is related to low patient self-esteem may have been due to our use of the Rosenberg measure, which has been criticised for its lack of specificity (Barrowclough et al, 2003). However, our finding that, in terms of relationships to expressed emotion, anxiety is a key feature in patients suggests that low self-esteem may be only

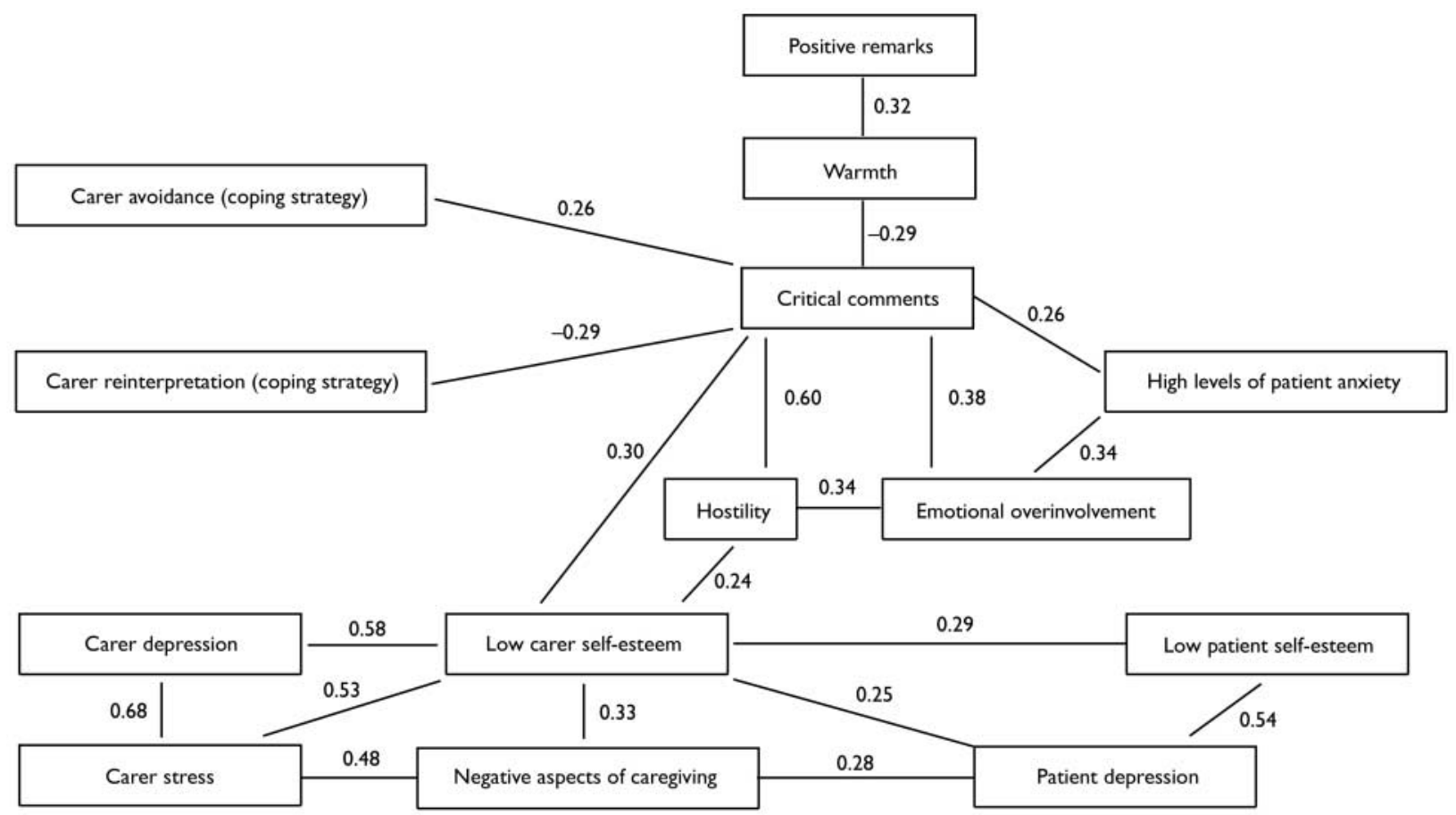

Fig. I Significant inter-correlations between attributes of carers and patients. 
one consequence of difficult relationships. The role of anxiety identified in this study revives the idea, first investigated in the 1970s, that high levels of arousal are related to relapse in people with schizophrenia who live with relatives who show high levels of expressed emotion (e.g. Tarrier et al, 1979; Sturgeon et al, 1981). It also links in with epidemiological evidence that anxiety is a central feature of the schizophrenia syndrome (Turnbull \& Bebbington, 2001).

Another limitation of our study was that all of the patients had experienced a relapse of their symptoms of psychosis within the past 3 months. This may have meant that we had 'ceiling' effects in our symptom measures, and if so, they were all likely to have been high. This would have reduced the variance, and it may offer a partial explanation for the low correlations.

This study was also limited by the fact that, even soon after a relapse, the levels of expressed emotion were lower than those reported in some other studies, yielding relatively few carers with high ratings. Low levels of criticism (with a mean of around three critical comments) may have reduced the power available for our analyses. There was no evidence that expressed emotion was not being rated appropriately. The low levels of expressed emotion may have been because our carer sample was largely located in Essex and Norfolk, rather than in inner-city locations in London. Fewer carers were identified in the innercity areas than elsewhere, and an appreciable number of these refused to participate in the trial. Recruitment was pursued vigorously, but this did not overcome the problem of some carers being unwilling to identify themselves as such, and others being unwilling to participate in a treatment trial, in line with the findings of some other recent studies (e.g. Szmukler et al, 2003).

The low levels of expressed emotion may on the other hand be a good sign, in that carers now have more resources available to them than they did when these studies began in the 1970s. The greater amount of information available, and the insistence in current UK clinical guidelines on schizophrenia that carers should themselves be the focus of clinical support (e.g. Department of Health, 1999; National Institute for Clinical Excellence, 2003), may have altered the behaviour and attitudes of some individuals who

\section{CLINICAL IMPLICATIONS}

Carer criticism seems to affect patients primarily by making them anxious.

- Patients whose carers had high levels of expressed emotion did not have more symptoms of psychosis than those whose carers had low expressed emotion soon after a relapse.

Family interventions should focus on reducing carer criticism and thereby decreasing patient anxiety, and improving carer self-esteem and carers' ability to cope.

\section{LIMITATIONS}

This was a cross-sectional study, which limits our ability to make causal inferences and investigate outcomes over time.

- The carers had lower mean levels of expressed emotion than in previous studies soon after a relapse, and this may have reduced the power available for our analyses.

- Because all of the patients had recently relapsed, there may have been less symptom variance to be explained.

E. KUIPERS, PhD, FBPsS, Department of Psychology, Institute of Psychiatry, King's College London, London; P. BEBBINGTON, PhD, FRCP, FRCPsych, Department of Mental Health Sciences, Royal Free and University College London Medical School, London; G. DUNN, PhD, Biostatistics Group, Division of Epidemiology and Health Sciences, University of Manchester, Manchester; D. FOWLER, MSc, School of Medicine, Health Policy and Practice, University of East Anglia, Norwich; D. FREEMAN, PhD, P.WATSON, MSc, A. HARDY, BSc, P. GARETY, PhD, FBPsS, Department of Psychology, Institute of Psychiatry, King's College London, London, UK

Correspondence: Professor E. Kuipers, Department of Psychology, PO Box 77, Institute of Psychiatry, King's College London, London SE5 8AF, UK. E-mail: e.kuipers@iop.kcl.ac.uk

(First received 3 December 2004; final revision 9 March 2005; accepted 22 March 2005)

found the demands of caring particularly difficult.

\section{Implications for family interventions}

High levels of criticism by carers appear to be the main feature of high expressed emotion that affects patients, and they possibly exert this effect via anxiety. We already know that high levels of anxiety in patients are associated with symptoms of psychosis that may precede relapse (Freeman \& Garety, 2003), and that they are an epidemiological feature of the schizophrenia syndrome (Turnbull \& Bebbington, 2001). In this case, anxiety may provide a more specific pathway for interventions, particularly family interventions. A key feature of family interventions has always been to reduce tension and improve negotiation, communication and problem-solving (Falloon et al, 1984; Anderson et al, 1986; Barrowclough \& Tarrier, 1992; Kuipers et al, 2002). The results of this study suggest that this route is particularly important.

The interrelationships between carer attributes confirm that carer stress, burden and poor coping strategies are related to the carer's own feelings. This suggests that family intervention may need to improve carer understanding of difficulties and optimise their coping strategies, moving the latter away from avoidance and towards reinterpretation or cognitive reappraisal. Improving these aspects might then reduce negative relationships (critical comments and hostility) and subsequently improve carer self-esteem, depression and care 'burden'. This might be the route to reducing the stress and burden of caring roles, which have been notably resistant to more general interventions (e.g. Barrowclough 
et al, 1999; Szmukler et al, 2003). Specific difficulties with carer self-esteem and depression, leading to negative evaluations of caregiving, might also be improved by interventions based on cognitivebehavioural therapy (e.g. Marriott et al, 2000). More targeted approaches in family intervention might enable us to improve both carer stress and patient outcomes.

\section{ACKNOWLEDGEMENTS}

We are grateful to all of the patients and their carers who consented to take part in the study, and to the clinical teams in the South London and Maudsley NHS Trust, Camden and Islington Mental Health and Social Care Trust, North East London Mental Health Trust and Norwich Mental Health Trust, who provided access to their clients. We also thank Louise Isham and Katherine Ruffell, who completed some of the assessments and ratings of expressed emotion. This study was funded by a Wellcome Trust Programme grant (no. 06452).

\section{REFERENCES}

Addington, D., Addington, J. \& Maticka-Tyndale, E. (1993) Assessing depression in schizophrenia: The Calgary Depression Scale. British Journal of Psychiatry, 163 (suppl. 22), 39-44.

Anderson, C. M., Reiss, D. J. \& Hogarty, G. E. (1986) Schizophrenia and the Family. New York: Guilford Publications.

Barrowclough, C. \& Tarrier, N. (1992) Families of Schizophrenic Patients: Cognitive Behavioural Intervention. London: Chapman \& Hall.

Barrowclough, C. \& Hooley, J. M. (2003) Attributions and expressed emotion: a review. Clinical Psychology Review, 23, 849-880.

Barrowclough, C., Tarrier, N., Lewis, S., et al (1999) Randomised controlled effectiveness trial of a needsbased psychosocial intervention service for carers of people with schizophrenia. British Journal of Psychiatry, 174, 505-5II.

Barrowclough, C., Tarrier, N., Humphreys, L., et al (2003) Self-esteem in schizophrenia: relationships between self-evaluation, family attitudes, and symptomatology. Journal of Abnormal Psychology, II2, 92-99.

Bebbington, P. \& Kuipers, L. (1994) The predictive utility of EE in schizophrenia: an aggregate analysis. Psychological Medicine, 24, 707-718.

Beck, A. T., Epstein, N., Brown, G., et al (1988) An inventory for measuring clinical anxiety: psychometric properties. Journal of Consulting and Clinical Psychology 56, 893-897.

Beck, A.T., Steer, R. A. \& Brown, G. K. (1996) $B D I-I$ Manual. San Antonio: The Psychological Corporation.

Birchwood, M., Iqbal, Z., Chadwick, P., et al (2000) Cognitive approach to depression and suicidal thinking in psychosis. I. Ontogeny of post-psychotic depression. British Journal of Psychiatry, 177, 516-528.

Butzlaff, R. L. \& Hooley, J. M. (1998) Expressed emotion and psychiatric relapse: a meta-analysis. Archives of General Psychiatry, 55, 547-552.

Carver, C. S. \& Scheier, M. F. (1994) Situational coping dispositions in a stress transaction. Journal of Personality and Social Psychology, 66, 184-195.

Carver, C. S., Scheier, M. F. \& Weintraub, J. K. (1989) Assessing coping strategies: a theoretically based approach. Journal of Personality and Social Psychology, 56 267-283.

Department of Health (1999) National Service Framework - Mental Health. London: Department of Health

Falloon, I. R. H., Boyd, J. L. \& McGill, C. W. (1984) Family Care of Schizophrenia. New York: Guilford Press.

Freeman, D. \& Garety, P. A. (2003) Connecting neurosis and psychosis: the direct influence of emotion on delusions and hallucinations. Behaviour Research Therapy, 41, 923-947.

Garety, P., Kuipers, E., Fowler, D., et al (2001) A cognitive model of the positive symptoms of psychosis. Psychological Medicine, 31, 189-195.

Goldberg, D. P. \& Williams, P. (1988) A User's Guide to the General Health Questionnaire.Windsor: NFER Nelson.

Kay, S. R. (1991) Positive and Negative Syndromes in Schizophrenia: Assessment and Research. New York: Brunner Mazel.

Kuipers, E., Leff, J. \& Lam, D. (2002) Family Work for Schizophrenia: a Practical Guide (2nd edn). London: Gaskell Press.
Leff, J. \& Vaughn, C. E. (1985) Expressed Emotion in Families. London: Guilford Press.

Marriott, A., Donaldson, C., Tarrier, N., et al (2000) Effectiveness of cognitive-behavioural family intervention in reducing the burden of care in carers of patients with Alzheimer's disease. British Journal of Psychiatry, 176, 557-562.

Marwaha, S. \& Johnson, S. (2004) Schizophrenia and employment. A review. Social Psychiatry and Psychiatric Epidemiology, 39, 337-349.

National Collaborating Centre for Mental Health (2003) Schizophrenia. Full National Clinical Guideline on Core Interventions in Primary and Secondary Care. London \& Leicester: Royal College of Psychiatrists \& British Psychological Society.

Raune, D., Kuipers, E. \& Bebbington, P. E. (2004) Expressed emotion at first episode psychosis: investigating a carer appraisal model. British Journal of Psychiatry, 184, 321-326.

Rosenberg, M. (1965) Society and the Adolescent SelfImage. Princeton, NJ: Princeton University Press.

Sturgeon, D., Kuipers, L., Berkowitz, R., et al (198I) Psychophysiological responses of schizophrenic patients to high and low expressed emotion relatives. British Journal of Psychiatry, 138, 40-45.

Szmukler, G. I., Burgess, P., Herrman, H., et al (1996) Caring for relatives with serious mental illness: the development of experience of caregiving inventory. Social Psychiatry and Psychiatric Epidemiology, 3I, 137-148.

Szmukler, G., Kuipers, E., Joyce, J., et al (2003) An exploratory randomised controlled trial of a support programme for carers of patients with a psychosis. Socia Psychiatry and Psychiatric Epidemiology, 38, 4II-4I8.

Tarrier, N., Vaughn, C. E., Laden, M. H., et al (1979) Bodily reactions to people and events in schizophrenia. Archives of General Psychiatry, 36, 31I-3I5.

Turnbull, G. \& Bebbington, P. (200I) Anxiety and the schizophrenic process: clinical and epidemiological evidence. Social Psychiatry and Psychiatric Epidemiology, 36, 235-243.

Vaughn, C. E. \& Leff, J. P. (1976) The influence of family and social factors on the course of psychiatric illness. British Journal of Psychiatry, 129, 125-137.

World Health Organization (1992) The ICD-IO Classification of Mental and Behavioural Disorders: Clinica Descriptions and Diagnostic Guidelines. Geneva: WHO. 